\title{
Entre lugares: das possibilidades da interculturalidade. Entrevista com Mariano Baez Landa
}

\section{Between places: from possibilities of interculturality. Interview with Mariano Baez Landa}

\section{Elissandra Barros da Silva Alexandre Herbetta}

O professor Mariano Baez landa possui longa e importante trajetória nos estudos da interculturalidade. Desde sua formação na instigante década de setenta até os dias atuais atua, como ele mesmo diz, de maneira engajada, apaixonada e aprofundada em temas centrais das sociedades latinoamericanas, como as relações interétnicas, a educação formal, a interculturalidade e a questão indígena. Destaca-se aí sua atuação como diretor de uma universidade intercultural mexicana.

Nesse período, ademais, estabeleceu uma relação muito próxima com o universo brasileiro, desde sua formação em nível de doutorado em Antropologia Social na Unicamp - Universidade de Campinas até sua presença em universidades brasileiras na década de 2010. Esta relação privilegiada o possibilita transitar entre os dois espaços e perceber questões e minúcias próprias de cada um deles como poucos.

Há pouco tempo, inclusive, passou duas longas temporadas junto à Universidade Federal de Goiás atuando como professor visitante e colaborando com o Programa de Pós-Graduação em Antropologia Social (PPGAS-UFG), onde lecionou disciplinas, orientou dissertações e teses e fez inúmeras pa- lestras, conferências e oficinas. Nesse período esteve muito presente junto ao Núcleo Takinahaky de Formação Superior Indígena (NTFSI), onde proferiu uma série de palestras e conferências acerca de temas que interconectam as experiências mexicana e brasileira nos campos em comentário.

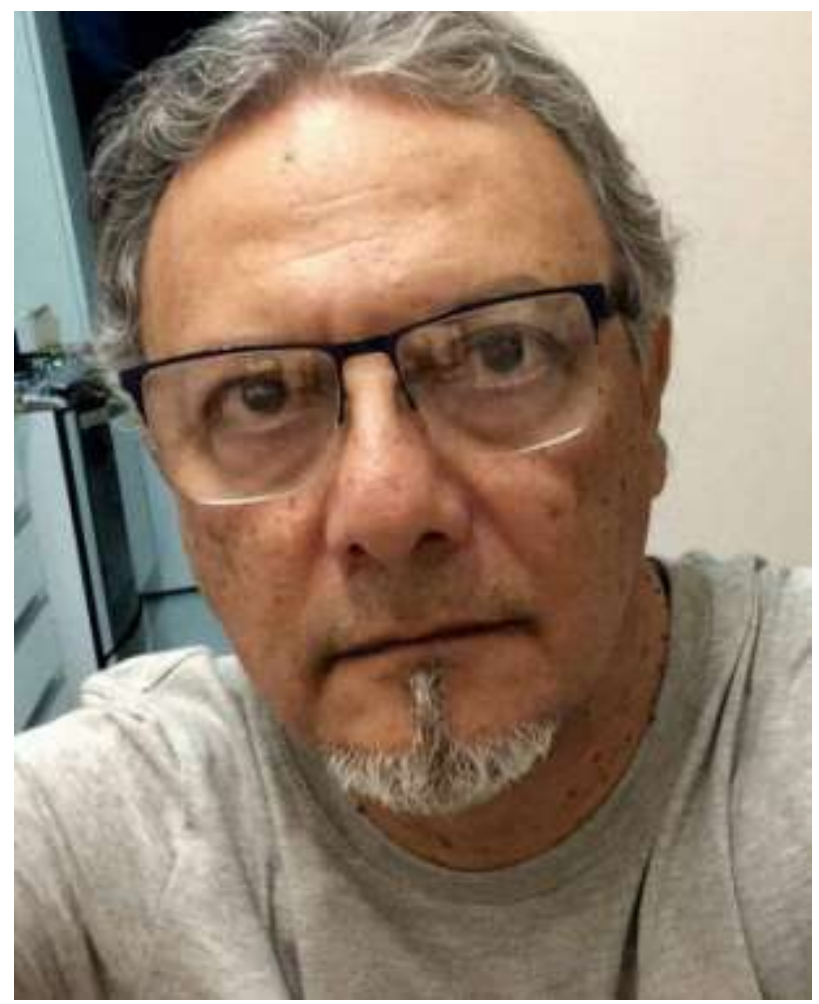

Imagem 1: Mariano Baez Landa

Dessa estada, dentre outras coisas, forta- 
leceu uma rede de colaboração entre o Brasil e o México, mais especificamente o Centro de Investigación y Estudios Superiores en Antropología Social (CIESAS), composta por pesquisadores e pesquisadoras indígenas e não indígenas de diversas outras instituições brasileiras. É a partir desta rede que se formou o GT Violência epistêmica e descolonização de Saberes: experiências recriadas e ressignificadas em espaços de interculturalidade na Asociación Latino Americana de Antropologia ALAS de Bogotá/Colômbia, realizado entre 6 e 9 de junho de 2017 na Pontificia Universidad Javeriana, onde Mariano participou como comentador. As apresentações, diálogos e debates deste evento são a base do dossiê aqui organizado.

A entrevista abaixo busca se aprofundar nos pontos acima mencionados, destacando a profícua formação de nosso entrevistado e a posição sui generis que ocupa atualmente, atuando com destaque em questões centrais para a América Latina, entre Brasil e México, o que lhe possibilita refletir profundamente sobre estes espaços e seus interstícios.

\section{TRAJETÓRIA ACADÊMICA}

Elissandra Barros e Alexandre Herbetta: Professor Mariano, você pode descrever brevemente sua trajetória acadêmica e o contexto político mexicano ao longo de sua formação? Como se colocava a perspectiva marxista nestes espaços e situações?

Mariano Baez Landa: Estudié la licenciatura en antropología en la universidad veracruzana durante la segunda mitad de los años setenta. Años de intensas luchas sociales y políticas en un contexto de represión sistemática de los gobiernos priístas responsa- bles de masacres estudiantiles, rurales y sindicales que tuvieron su mas alta expresión en la matanza de 02 de Octubre de 1968 en la Plaza de Tlatelolco de la Ciudad de México donde fueron asesinadas miles de personas a manos de fuerzas combinadas de ejército y cuerpos paramilitares al mando del propio presidente Gustavo Díaz Ordaz, su ministro de gobernación Luis Echeverría Alvarez, el ministro de la defensa Marcelino García Barragán y el jefe de la policía política Fernando Gutiérrez Barrios. Toda la década de los años setenta fueron "anos de chumbo", porque fueron el escenario también de los movimentos guerrilleros mexicanos que surgieron en las ciudades y el campo. Pertenezco a una tradición política que se inspira en la idea de luchar mientras se estudia con dedicación, perseverancia y pasión.

La formación del estudiante mexicano de antropología hasta prácticamente la década de los años setenta fue dominada por la tradición empirista. Los trabajos recepcionales de estos antropólogos eran estudios de corte histórico-cultural con poca profundidad etnográfica y etnológica o bien de perfil estructural-funcional con un marcado enfoque de comunidad y presentados en forma de monografías que se inspiraban en la antropología aplicada indigenista.

A partir del movimiento estudiantil de 1968 la mayoría de las escuelas de antropología mexicanas comienzan a incorporar el pensamiento marxista a sus programas de estudio y a las metodologías de sus investigaciones. Uno de los primeros resultados, en el área de antropología social, es el abandono del tema indigenista como parcela prioritaria de los esfuerzos académicos y el emprendimiento de los estudios campesinos, de las colonias populares y de la migración rural- 
urbana. En todos ellos, con raras excepciones, la lectura dogmática del marxismo afirmó en el discurso antropológico mexicano los esquemas evolucionistas y profundizó la tendencia por explicar a la sociedad a través de determinantes económicos.

De alguna manera fue el mismo contexto donde estudié la maestría en antropologia social (CIESAS 1988-1991) y que registró la primera gran batalla electoral del pueblo mexicano venciendo al partido de estado $\mathrm{PRI}$ en los comícios presidenciales, triunfo que fué aplastado por la soberbia y la prepotência de una máfia que hizo de la revolución mexicana una institución de la corrupción, el saqueo de las riquezas nacionales, la violência y de una ditadura de partido.

El gremio antropológico debatía en esos años, entre las posiciones campesinistas y las proletaristas, reproduciendo a escala una supuesta y fundamental contradicción entre la tradición y la modernidad. Lo mismo ocurría en el terreno de la cuestión de las nacionalidades, donde los parámetros eran el llamado etnopopulismo y las interpretaciones de un marxismo ortodoxo, autoritario y mecanicista.

México se descubre nuevamente a partir de 1988, como el país de la diversidad, como una sociedad multicultural, donde tradición y modernidad interactuan intensamente, dándole rasgos de particularidad a varias configuraciones socioculturales, que conforman un verdadero mosaico de regiones y espacios sociales en movimiento.

Las luchas europeas de 1989 contra el autoritarismo de los partidos-Estado del socialismo real, vinieron a confirmar lo que estábamos descubriendo en México. Frente a los ojos del investigador social se desarrollaba un verdadero quiebre paradigmático; surgían nuevos actores o se revitalizaban otros; las sociedades estudiadas ya no eran las mismas; las preguntas y respuestas a sus fenómenos tampoco podían serlo.

Durante los años 90's se plantearon medidas económicas y políticas que pretendían modernizar al país; insertarlo en un esquema global e internacional de liberalismo económico, para elevarlo a la categoría de potencia intermedia entre el llamado tercer mundo y los países centrales.

Una vez más se escucharon voces encontradas acerca del destino final de las tradiciones y las identidades de lo propio, frente a una virtual integración económico-regional de México, Estados Unidos y Canadá donde prevalecería lo ajeno.

Unos ratificaron la convicción de que el cambio social se determinaba por una racionalidad económica universal que, en este caso, procede del exterior; otros por el contrario, creían posible reeditar un nacionalismo estatal, que reconstruyera un esquema de desarrollo más autónomo.

El Tratado de Libre Comercio de América del Norte y las medidas de apertura y desregulación, que el Estado aplicó a la economía mexicana, fueron vistas como amenazas a una identidad y soberanía nacionales.

Finalmente en 1994, viajé a Brasil para estudiar el doctorado en ciências sociales en la Universidad Estatal de Campinas, enmedio del levantamento armado del EZLN en el estado de Chiapas.

Estudei antropologia na Universidade Veracruzana durante a segunda metade dos anos setenta. Anos de lutas sociais e políticas intensas em um contexto de repressão sistemática efetivada pelos governos do PRI responsáveis por massacres de estudantes, camponeses e operários, que teve sua má- 
xima expressão no massacre de 02 de outubro de 1968 na Praça de Tlatelolco na Cidade do México, onde foram assassinados milhares de pessoas pelas forças combinadas do exército e forças paramilitares sob o comando do presidente Gustavo Diaz Ordaz, pelo ministro Luis Echeverria Alvarez, pelo ministro da defesa Marcelino Garcia Barragan e pelo chefe da polícia política Fernando Gutiérrez Bairros. Toda a década dos anos setenta foram "anos de chumbo" porque também foram palco de movimentos guerrilheiros que surgiram nas cidades e no campo. Eu pertenço a uma tradição política que é inspirada pela ideia de lutar enquanto se estuda, e tentei sempre agir com dedicação, perseverança e paixão.

A formação do estudante mexicano de antropologia até praticamente a década de setenta foi dominada pela tradição empirista. As teses de graduação focaram em estudos monográficos de tipo histórico-cultural com pouca profundidade etnográfica e etnológica, mas também foram feitos trabaIhos com um perfil estrutural-funcional com foco nas comunidades e que foram apresentados sob a forma de monografias, inspiradas pela antropologia aplicada indigenista.

A partir do movimento estudantil de 1968, a maioria das escolas de antropologia mexicana começou a incorporar o pensamento marxista em seus programas de estudo e metodologias de pesquisa. Um dos primeiros resultados na área de antropologia social é o abandono da questão indígena como uma prioridade dos esforços acadêmicos e um foco nos estudos das sociedades camponesas, das populações urbanas e marginais e da migração rural-urbana. Em todos eles, com exceções, uma leitura dogmática do marxismo fortaleceu o paradigma evolucionista e aprofundou a tendência de explicar a sociedade pelos determinantes econômicos.

De alguma forma o contexto foi o mesmo onde estudei mestrado em antropologia social (CIESAS 1988-1991) no período da primeira batalha eleitoral importante do povo mexicano, derrotando o partido PRI na eleição presidencial, o que foi esmagado pela arrogância de uma máfia que fez da revolução mexicana uma instituição de corrupção, pilantragem, violência em forma de partido de estado.

O grêmio antropológico lutou naqueles anos, entre as posições campesinas e proletárias, reproduzindo uma suposta contradição fundamental entre a tradição e a modernidade. O mesmo aconteceu no campo da questão nacional, onde os parâmetros do debate se fixaram entre o chamado etnopopulismo e as interpretações do marxismo ortodoxo, autoritário e mecanicista.

O México é novamente descoberto no ano de1988, como o país da diversidade, como uma sociedade multicultural, onde a tradição e a modernidade interagem intensamente, produzindo várias configurações socioculturais, que compõem um mosaico de regiões e espaços sociais em movimento.

As lutas europeias em 1989 contra um partido-estado socialista-autoritário veio confirmar o que estávamos descobrindo no México. Na frente dos olhos do pesquisador social, uma ruptura paradigmática real foi desenvolvida; novos atores emergiram ou outros se revitalizaram; as sociedades estudadas não eram mais as mesmas; as perguntas e respostas aos seus fenômenos também não poderiam ser.

Durante os anos 90 foram propostas medidas econômicas e políticas que buscavam modernizar o país; inseri-lo em um esque- 
ma de liberalismo econômico global e internacional para elevá-lo à categoria de potência intermediária entre o Terceiro Mundo e os países centrais. Mais uma vez se escutaram vozes que falaram do destino final das tradições e identidades nativas na frente de uma integração econômica regional de México, EUA e Canadá. Alguns ratificaram a convicção de que a mudança social era determinada por uma racionalidade econômica universal que, nesse caso, vem de fora; outros, pelo contrário, acharam possível restaurar um nacionalismo de estado, para reconstruir um esquema de desenvolvimento mais autônomo.

O Acordo de Livre Comércio da América do Norte e as medidas de abertura e de desregulamentação que o Estado aplicou à economia mexicana eram vistos como ameaças à identidade e soberania nacionais.

Finalmente, em 1994, eu viajei ao Brasil para estudar doutorado em Ciências Sociais pela Universidade Estadual de Campinas, no mesmo momento do levante do EZLN no estado de Chiapas.

\section{Elissandra Barros e Alexandre Herbetta:}

Qual era a situação do campo de estudos da interculturalidade e da educação escolar indígena no momento de sua formação $e$ como você se encaminhou para estes temas? Por favor, faça uma breve contextualização da formação destes campos de estudo e pesquisa no México.

Mariano Baez Landa: La práctica antropológica mexicana está ligada fuertemente con las acciones indigenistas en el campo educativo como estratégia central en el processo de integración nacional. Desde la misma creación del Ministerio de Educación del nuevo régimen de la revolución mexica- na con José Vasconcelos a la cabeza, se consideró como tarea central la enseñanza del idioma castellano en las áreas indígenas, el espacio para llevarla a cabo fue la escuela rural. La labor educativa en su conjunto debia lograr la integración de la vida económica, política y social de los indígenas, haciendo prevalecer los beneficios de la ciencia y la técnica de la era industrial. Durante la primera mitad del siglo XX México transitó de un esquema de educación rural basado en un positivismo racionalista y pragmático; pasó por una cresta socialista con marcadas influencias de la escuela racional y anarquista y declinó hacia un proyecto acorde con la estructura capitalista y dependiente a la que se abrió México después de la Segunda Guerra Mundial. La acción indigenista había privilegiado la tesis incorporacionista, con el objetivo de dotar a México de un solo idioma, en este caso el castellano. Esa castellanización quasi forzosa, estuvo presente tanto en los profesores misioneros de Vasconcelos, las misiones Culturales de Sáenz como en la Escuela Rural de Rafael Ramírez y la educación socialista del mismo Bassols. En todos los casos la castellanización fue pensada como un vehículo civilizador, como el acto más noble del Estado a favor del desarrollo.

La postura integracionista del nuevo indigenismo veía en el bilingüismo, como castellanización en lengua materna, un instrumento que buscaba el consenso basado en el relativismo cultural (AGUIRRE BELTRÁN, 1994). La propuesta bilingüe tenía un sustrato bicultural pero lamentablemente su aplicación concreta solo fortaleció el proceso de asimilación de la población india al proyecto occidental. A partir de los movimentos indígenas y afrodescendentes de la década de los años 90 , reivindicativos de autonomias y proyectos autonómicos donde destaca en primer tér- 
mino el levantamento armado del EZLN, fue creciendo la idea de que las acciones asimilasionistas, integracionistas, participacionistas de los estados englobaban prácticas de violência cultural y epistémica en las relaciones interétnicas que tenían que ser combatidas con un nuevo modelo de relaciones sociales que apunte a prácticas de reconocimiento, respeto y convivência entre los diversos componentes de sociedades étnica y culturalmente diversas y diferenciadas. La fuerza de estos movimentos y la diversidade de respuestas de los estados reconfiguró nuevos escenarios de intervención de Ixs antropologxs para estudiar la dinâmica de las relaciones interétnicas en la era global. Es en ese contexto que tengo la oportunidade de dirigir la Universidad Veracruzana Intercultural entre 2011 y 2013.

A prática antropológica mexicana está fortemente ligada às ações indigenistas no campo educacional como estratégia central no processo de integração nacional. Desde a criação do Ministério da Educação do novo regime da Revolução Mexicana com José Vasconcelos na frente, o ensino de língua castelhana em áreas indígenas foi considerada como tarefa central. $O$ espaço para sua realização foi a escola rural. O trabalho educativo visava a integração da vida econômica, política e social dos povos indígenas, fazendo prevalecer os benefícios da ciência e da tecnologia da idade industrial. Durante a primeira metade do século $X X, 0$ México passou de um esquema de educação rural baseado num positivismo racionalista e pragmático; para uma perspectiva socialista com fortes influências da escola anarquista racional, e declinou para um projeto de acordo com a estrutura capitalista dependente, que abriu o México após a
Segunda Guerra Mundial. A ação indigenista privilegiou a tese incorporacionista, com o objetivo de proporcionar ao México apenas uma língua, neste caso o espanhol. A castelhanização era pensada como um veículo civilizador, como o ato mais nobre do Estado em favor do desenvolvimento.

A posição integracionista de um novo indigenismo viu no bilinguismo, como a casteIhanização na língua materna, um instrumento que procurava consenso, baseado num relativismo cultural (AGUIRRE BELTRAN). A proposta bilíngüe tinha um substrato bicultural, mas infelizmente sua aplicação concreta apenas fortaleceu o processo de assimilação da população indígena ao projeto ocidental. A partir dos movimentos indígenas e afroamericanos da década dos anos 90 , os quais reivindicam autonomias e projetos autônomos, destacando em primeiro lugar o levante do EZLN, cresceu a ideia de que ações assimilacionistas, integracionistas, participacionistas dos estados geravam práticas culturais e violência epistêmica nas relações interétnicas e tiveram que ser combatidos com um novo modelo de relações sociais que apontam para práticas de reconhecimento, respeito e para a coexistência pacífica entre os vários componentes das sociedades étnicas e culturalmente diversas e diferenciadas. A força desses movimentos e a diversidade de respostas estatais reconfiguraram novos cenários de intervenção dos antropólogos para estudar a dinâmica das relações interétnicas na era global. É neste contexto que tenho a oportunidade de dirigir a Universidade Intercultural de Veracruz entre 2011 e 2013.

No Brasil percebemos que a interculturalidade está intimamente ligada à questão 
indígena, seja por meio do movimento indígena em si e a demanda por educação diferenciada, seja através do campo da etnologia indígena. Como a área da antropologia mexicana, especificamente, tratava da educação intercultural?

Mariano Baez Landa:El campo de la interculturalidad es el mismo de las relaciones sociales étnica y culturalmente diferenciadas. La antropologia da la mayor importância a la dinâmica de las relaciones interétnicas tomando como categoria central a la cultura. No obstante, en México se transita de las estratégias de educación indígena castellanizadora, de educación bilíngue y bicultural hasta la educación intercultural pero sin abandonar la raíz integracionistahegemónica de la sociedade mestizooccidental.

O campo da interculturalidade é o mesmo do das relações sociais étnica e culturalmente diferenciadas. A antropologia dá a maior importância à dinâmica das relações interétnicas, tomando a cultura como categoria central. No entanto, no México, partese das estratégias de educação indígena castelhanizadora, da educação bilingue e bicultural para a educação intercultural, sem abandonar a raiz integracionistahegemónica da sociedade mestiçaocidental.

\section{CONTEXTO DA EDUCAÇÃO INTERCULTU- RAL}

\section{Elissandra Barros e Alexandre Herbetta:} Apesar dos avanços em relação aos temas em questão, nos chama muito a atenção a experiência das Universidades Indígenas ou Interculturais, tema ainda tratado de ma- neira superficial no Brasil. Como se sabe, a interculturalidade e a Educação Escolar Indígena aparecem como mais um curso ou programa em universidades federais e estaduais. Conte-nos sobre sua experiência como diretor de uma universidade intercultural no México.

Mariano Baez Landa: Las universidades interculturales mexicanas son proyectos educativos que surgieron impulsados por la Secretaría de Educación Pública a partir del año 2000 durante el sexenio de Vicente Fox, por cierto el primer presidente mexicano que rompió la hegemonía del PRI, la máquina institucional que consolidara el presidente Cardenas 60 años atrás. Debe anotarse aquí la excepción de la Universidad Autónoma Indígena de Mexico (UAIM) en Sinaloa, que fue creada originalmente como un proyecto de docencia e investigación etnológica en 1982. Las demás universidades interculturales dependen primordialmente del financiamiento estatal y federal, asi como de las decisiones que tomen sobre ellas los gobernantes. Su propósito institucional es explorar modalidades de atención educativa pertinente para jóvenes que aspiren a cursar el nivel de educación superior, tanto de origen indígena como de otros sectores sociales, interesados en impulsar fundamentalmente el desarrollo de los pueblos y comunidades indígenas y en aplicar los conocimientos construidos en contextos culturalmente diversos. Algunas personas afirman que fue una conquista del movimiento zapatista de 1994, otras las identifican como una estrategia del gobierno Fox para cooptar demandas del movimiento indígena. De manera personal tuve la oportunidad de dirigir por un poco mas de 2 años a la Universidad Veracruzana Intercultural, úni- 
co programa de educación superior intercultural mexicano que surge al interior de una universidad estatal convencional. Los programas de educación intercultural hasta ahora, insertos en el modelo educativo nacional, no son mas que una perversión pedagógica porque plantea un diálogo de saberes horizontal y simétrico entre culturas, pasando por alto la determinación de un sistema social cuyas relaciones son asimétricas y se encuentran enmarcadas por estructuras de poder y dominación. En no pocos casos se habla de interculturalidad como un nuevo paradigma educativo, como una nueva pedagogía que promueve la discriminación positiva de los indios, su autoreconocimiento y afirmación étnico cultural para apropiarse de los conocimientos occidentales e incorporarlos a un universo epistémico inmutable, conservador y en constante resistencia. Esta postura tiene una buena dosis de relativismo, donde el propio concepto de cultura se confunde con una identidad étnica sempiterna. El término interculturalidad ha virado moda en los últimos años, como un adjetivo que califica mágicamente cualquier planteamiento $\mathrm{y}$ acción que dice reconocer y atender la diversidad cultural, utilizando un discurso políticamente correcto de defensa a ultranza de las tradiciones, costumbres y conocimientos ancestrales de los llamados pueblos originarios (muchas veces lesionando los derechos de terceras personas) como un imperativo ético-político frente a las amenazas del capitalismo neoliberal. Así, se habla incluso de la interculturalidad como un nuevo estadio de desarrollo humano, como proyecto cultural alternativo que presupone un plano horizontal de comunicación, intercambio y cooperación del conocimiento. Evidentemente esta interculturalidad idílica no corresponde a la experiencia del mundo vivo, el cual se encuentra atravesado por las categorías de etnia, raza, clase, género y sexualidad, y donde se condensan las relaciones sociales basadas en la fricción, el conflicto, la negación del otro, el racismo, la desigualdad económica, la homofobia, el sexismo, la violencia y el miedo a la diferencia.

As universidades interculturais mexicanas são projetos educacionais que surgiram impulsionados pelo Ministério da Educação de 2000 durante a presidência de Vicente Fox, na verdade, o primeiro presidente mexicano que quebrou a hegemonia do PRI, máquina institucional que consolidara 0 presidente Cardenas 60 anos atrás. Deve-se notar aqui a exceção da Universidade Autônoma Indígena do México (UAIM) em Sinaloa, que foi originalmente criada como um projeto de ensino e pesquisa etnológica em 1982. As outras universidades interculturais dependem de investimentos diretos dos governos estaduais e do governo federal. Sua finalidade institucional é explorar modalidades de serviços educacionais apropriados para os jovens que aspiram a prosseguir a nível do ensino superior, tanto de origem indígena quanto de outros setores sociais interessados em promover fundamentalmente o desenvolvimento dos povos e comunidades indígenas e aplicar o conhecimento construído em contextos culturalmente diversos. Algumas pessoas dizem que foi uma conquista do movimento zapatista de 1994, outros falam de uma estratégia do governo Fox para cooptar demandas do movimento indígena. Pessoalmente, eu tive a oportunidade de dirigir a Universidade Veracruzana Intercultural, único programa mexicano de ensino superior inter- 
cultural que surge dentro de uma universidade estadual convencional. Os programas de educação intercultural, até agora, são apenas uma perversão pedagógica porque buscam um diálogo de saberes horizontal e simétrico, ignorando as determinações de um sistema social cujas relações são assimétricas e estão enquadradas por estruturas de poder e dominação. Em muitos casos, se fala da interculturalidade como um novo paradigma educacional, como uma nova pedagogia que promove a discriminação positiva dos índios, seu autoreconhecimento e afirmação étnica cultural para apropriar-se do conhecimento ocidental e incorporá-lo num universo epistêmico imutável, conservador e numa resistência constante. Esta posição tem uma boa dose de relativismo, onde o próprio conceito de cultura é confundido com uma identidade étnica sempiterna. $O$ termo interculturalidade se tornou moda nos últimos anos, como um adjetivo que qualifica qualquer abordagem e ação que diz reconhecer e lidar com a diversidade cultural, usando um discurso politicamente correto na defesa intransigente das tradições, costumes e conhecimentos ancestrais dos chamados povos indígenas (muitas vezes ferindo os direitos de terceiros) como um imperativo ético e político frente as ameaças do capitalismo neoliberal. A interculturalidade idílica não corresponde à experiência do mundo vivo, que é atravessado pelas categorias de etnia, raça, classe, gênero e sexualidade, e onde as relações sociais estão baseadas na fricção, no conflito, na negação do outro, no racismo, na desigualdade econômica, na homofobia, no sexismo, na violência e medo da diferença.
Elissandra Barros e Alexandre Herbetta: Um dos aspectos que chama a atenção em sua trajetória é o íntimo contato com a realidade brasileira e a possibilidade de fazer comparações profundas e efetivas entre os dois países. $O$ que você chamaria a atenção no que se refere à formação em antropologia aqui e lá? Há autores/autoras que fazem a mediação entre os dois espaços? $O$ que se conhece da antropologia mexicana no Brasil e vice-versa?

Mariano Baez Landa: Las antropologías mexicana y brasileira son las dos mas grandes de América Latina, sus relaciones de intercambio y cooperación tienen antecedentes marcados desde mediados del siglo $X X$ y que se incrementan con la participación de Guillermo Bonfil Batalla como profesor visitante del programa de posgrado en antropología de la Universidad Federal de Río de Janeiro en 1970, que había sido fundado apenas dos años antes, y con la estancia de Roberto Cardoso de Oliveira en el entonces CISINAH (hoy CIESAS), dirigido por Bonfil Batalla, a finales de la década de los años setenta invitado para colaborar con el programa de doctorado. En un momento anterior la interacción entre nuestras antropologías tuvo signos de fricción y alejamiento, debido a una particular percepción del carácter ideológico del programa indigenista mexicano por los delegados brasileiros que asistieron al primer congreso indigenista interamericano en Pátzcuaro durante 1940. Las diferencias y semejanzas entre México y Brasil son de alto contraste, pero su estudio comparativo puede brindarnos grandes enseñanzas en los terrenos de la formación de los estados nacionales, del carácter y transformación de políticas públicas dirigidas a grupos vulnerables, de las 
identidades étnicas, del trato a los pueblos indios y sus derechos, de las transformaciones de sus ámbitos rural y urbano y de los procesos de construcción de diversas ciudadanías en un contexto nacional poderosamente influenciado por la globalización.

As antropologias mexicana e brasileira são as duas maiores da América Latina, suas relações de troca e de cooperação têm uma história marcada desde meados do século XX e aumentam com a participação de Guillermo Bonfil Batalla como professor visitante do programa de pós-graduação em antropologia da Universidade Federal do Rio de Janeiro em 1970, e a estada de Roberto Cardoso de Oliveira na mesma década no CISINAH (agora CIESAS), chefiado por Bonfil Batalla, para colaborar com o programa de doutorado. Numa etapa anterior, nossas antropologias tiveram sinais de friç̧ão e afastamento devido a uma percepção particular do caráter ideológico do programa indigenista mexicano por parte dos delegados brasileiros que participaram do primeiro Congresso Indigenista Interamericano em Patzcuaro durante os anos 1940. As diferenças e semelhanças entre o México e Brasil são de alto contraste, mas seu estudo comparativo pode dar-nos grandes lições nos fundamentos da formação dos estados nacionais, do caráter e transformação das políticas públicas dirigidas a grupos vulneráveis, das identidades étnicas, do tratamento aos povos indígenas e seus direitos, das transformações de suas áreas rurais e urbanas e dos processos de construção de diversas cidadanias no contexto nacional fortemente influenciado pela globalização

\section{EXPERIÊNCIA NO BRASIL E POSSÍVEIS COMPARAÇÕES}

\section{Elissandra Barros e Alexandre Herbetta: Como vê a realidade indígena no Brasil?}

Mariano Baez Landa: Actualmente percebo renovados ataques al corazón de los pueblos indígenas de Brasil a manos de la bancada triple B de fazendeiros latifundistas, políticos corruptos y repressivos asi como empresários de diversas religiones evangélicas. Apunto un retrocesso sensible de conquistas obtenidas a partir de la directas y un repunte de diversos movimentos indígenas principalmente en defensa de su território. En comparación con México la población indígena brasileira es bastante menor y se encuentra dispersa en pequeños bolsones dentro de sus territórios, no obstante su migración a las ciudades es cada día más fuerte y lucha por espacios en diversas áreas e instituciones de la sociedade de los blancos.

Atualmente percebo novos ataques ao coração dos povos indígenas do Brasil realizado pela bancada do triplo $B$, de fazendeiros latifundiários, políticos corruptos e repressores, bem como empresários de várias religiões evangélicas. Aponto um retrocesso sensível das conquistas obtidas a partir do movimento das diretas e um reavivamento de vários movimentos indígenas, principalmente na defesa de seu território. Em comparação com o México, a população indígena brasileira é bastante pequena e está dispersa em pequenos bolsões dentro de seus territórios, embora sua migração para as cidades esteja se fortalecendo e estejam lutando por espaços em diferentes áreas e instituições da sociedade dos brancos. 
Elissandra Barros e Alexandre Herbetta: $E$ possivel observar diferenças na forma como a interculturalidade está sendo concebida e empregada no campo da educação escolar indígena no Brasil e no México?

Mariano Baez Landa: Es bastante clara la diferencia entre los programas brasileiros y mexicanos. En México la educación escolar indígena básica y secundaria no contempla el enfoque intercultural, mientras que en las llamadas universidades interculturales este enfoque parece significar solo la inclusión de estudiantes indígenas a programas universitarios convencionales. En Brasil observo un compromisso mas profundo con el enfoque intercultural, especialmente con una visión formativa de docentes indígenas de nível básico que irán a implementar programas político-pedagógicos en sus aldeas y pueblos para recuperar el control cultural de su vida comunitária. Las iniciativas de inclusión de estudiantes indígenas en el nível universitário han tomado relevância en los últimos años pero se enfrentan al peso de la hegemonia monocultural y monoepistémica del modelo universitário occidental.

A diferença entre os programas brasileiro e mexicano é bastante clara. No México, a educação escolar indígena básica e secundária não contempla a abordagem intercultural, enquanto nas chamadas universidades interculturais essa abordagem parece significar apenas a inclusão de estudantes indígenas em programas universitários convencionais. No Brasil, vejo um compromisso mais profundo com a abordagem intercultural, especialmente com uma visão formativa de professores indígenas de nível básico que implementarão programas político- pedagógicos em suas aldeias e cidades para recuperar o controle cultural de sua vida comunitária. As iniciativas de inclusão de estudantes indígenas no nível universitário tomaram relevância nos últimos anos, mas enfrentam o peso da hegemonia monocultural e monoepistêmica do modelo universitário ocidental.

Elissandra Barros e Alexandre Herbetta: A partir de sua experiência, o que poderia destacar no campo da educação intercultural e da educação escolar indígena no Brasil? Na mesma direção, o que vê no México que pode ser interessante de se pensar no Brasil?

Mariano Baez Landa: [Parte de la respuesta está arriba] Es importante pensar en torno a que la interculturalidad realmente existente, se compone de aproximaciones emprendidas desde varias ópticas culturalmente diferenciadas, para construir puentes entre poblaciones e individuos de culturas distintas. Parte de un concepto dinámico y diacrónico de la cultura que se desarrolla en escenarios de relaciones sociales asimétricas y enmarcadas por estructuras de poder. Es ante todo una interfase comunicativa que aspira a crear competencias suficientes que hagan posible un verdadero diálogo entre culturas. Por ello el llamado diálogo de saberes solo puede establecerse entre las culturas realmente existentes, que producen nuevos componentes y que se apropian de otros, que se transforman y adaptan permanentemente para no desaparecer o ser asimiladas.

[Parte da resposta está acima] É importante pensar sobre o fato de que a interculturalidade realmente existente, consiste em 
abordagens realizadas a partir de várias perspectivas culturalmente diferenciadas, que atuam para construir pontes entre populações e indivíduos de diferentes culturas. Parte-se de um conceito dinâmico e diacrônico da cultura que se desenvolve em cenários de relações sociais assimétricas e enquadradas por estruturas de poder. É sobretudo uma interface comunicativa que aspira a criar competências suficientes que possibilitem um verdadeiro diálogo entre culturas. Portanto, o chamado diálogo do conhecimento só pode ser estabelecido entre as culturas realmente existentes, que produzem novos componentes e que se apropriam de outros, que são transformados e adaptados permanentemente para não desaparecer ou ser assimilados.

\section{DECOLONIALIDADE, EDUCAÇÃO ESCOLAR E UNIVERSIDADES}

Elissandra Barros e Alexandre Herbetta: Nos últimos anos é crescente a discussão sobre a decolonização de saberes, o que pode ser observado pelo número de trabaIhos teóricos, estudos de caso e eventos acadêmicos que se debruçam sobre questões decoloniais, nas diferentes áreas do conhecimento. Como você avalia essa discussão e seu impacto nas universidades?

Mariano Baez Landa: Lo importante aqui es diferenciar entre el discurso y las practicas decoloniales. Rivera Cusicanqui y Walsh advierten del peligro de perversión del discurso decolonial como discurso politicamente correcto y como nuevo paradigma de dominación del mundo de los blancos sobre los 'otros'. Las practicas decoloniales, a mi entender, deben partir del corazón mismo de los colonizados, de processos de generación de nuevas epistemologias que enfrenten la hegemonia occidental. El primer passo es que los colonizados se reconozcan a si mismos como tales y diseccionen la matriz colonial que los somete con conocimientos propios y una recuperación del control cultural sobre su vida social.

O importante aqui é diferenciar o discurso e as práticas decoloniais. Rivera Cusicanqui e Walsh alertam para o perigo da perversão do discurso decolonial como discurso politicamente correto e como novo paradigma de dominação do mundo dos brancos sobre os "outros". As práticas decoloniais, em minha opinião, devem partir do próprio coração do colonizado, dos processos de geração de novas epistemologias que confrontam a hegemonia ocidental. 0 primeiro passo é que os colonizados se reconheçam como tal e dissequem a matriz colonial que os sujeitam com seus próprios conhecimentos e consigam uma recuperação do controle cultural sobre sua vida social.

Elissandra Barros e Alexandre Herbetta: No Brasil a presença de indígenas nas universidades ainda é incipiente, geralmente concentrados nos cursos de Licenciatura Intercultural Indígena. Contudo, com a criação e implementação de políticas de acesso e permanência nas universidades voltadas para a população indígena, a tendência é que o acesso seja ampliado e diversificado, refletindo na formação de indígenas nas mais diferentes áreas e no acesso destes aos cursos de Mestrado e Doutorado. Como você avalia esse processo de "indianização" das Universidades? 
Mariano Baez Landa: Hablar de la democracia en las universidades públicas como proceso de inclusión de personas étnica y culturalmente diferenciadas tiene varios problemas. Así la universidad se democratiza en la medida que incluye nuevos estudiantes por ser negros, indígenas, etc? Pero aquí el asunto es que tal inclusión no transforma la estructura básica de la universidad occidental y sí afirma un proceso de integración cultural y etnico en la universalidad de las instituciones de enseñanza superior. El espíritu universalista de la universidad forma y reproduce una educación monocultural entre sus miembros, una cultura llamada ciencia. Esta universalidad golpea directamente en la propuesta de educación intercultural basada en un principio de reconocimiento, respeto y convivencia de la diversidad sociocultural. Se necesita discutir el carácter y el alcance de una democracia racial, cultural y étnica cuando se afirma un fortalecimiento y profundización de las diferencias. Por otro lado, es altamente instigador profundizar investigaciones que tengan en cuenta el impacto de la inserción universitaria en la producción y reproducción de los saberes y conocimientos de los pueblos originarios, especialmente aquellas prácticas que pueden estar provocando una violencia epistémica al intentar encajar los conocimientos indígenas en un modelo científico occidental.

Falar da democracia nas universidades públicas como processo de inclusão de pessoas étnica e culturalmente diferenciadas tem vários problemas. Assim a universidade se democratiza na medida que inclui novos estudantes por serem negros, indígenas, etc? Mas aqui o assunto é que tal inclusão não transforma a estrutura básica da uni- versidade ocidental e sim afirma um processo de integração cultural e étnico na universalidade das instituições de ensino superior. O espírito universalista da universidade formata e reproduz uma educação monocultural entre seus membros, uma cultura chamada de ciência. Essa universalidade vai de encontro à proposta de educação intercultural baseada num princípio de reconhecimento, respeito e convivência da diversidade sociocultural. Precisa-se discutir o caráter e o alcance de uma democracia racial, cultural e étnica quando se afirma um fortalecimento e aprofundamento das diferenças. Por outro lado, é altamente instigante aprofundar pesquisas que se atentem ao impacto da inserção universitária na produção e reprodução dos saberes e conhecimentos dos povos originários, especialmente aquelas práticas que podem estar provocando uma violência epistêmica ao tentar encaixar os conhecimentos indígenas num modelo científico ocidental.

Xalapa, Ver. México 18 de Abril de 2018 